\title{
Development and Characterization of Composite Materials for Production of Composite Risers by Filament Winding
}

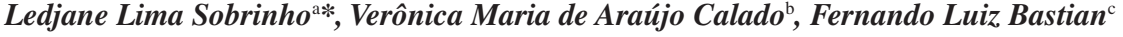 \\ ${ }^{a}$ Curso de Engenharia de Materiais, Universidade Federal do Ceará - UFC, Campus Cariri, \\ Av. Tenente Raimundo Rocha, s/n, CEP 63040-360, Juazeiro do Norte, CE, Brazil \\ ${ }^{\mathrm{b}}$ Departamento de Engenharia Química, Escola de Química, \\ Universidade Federal do Rio de Janeiro - UFRJ, CP 68542, \\ CEP 21949-900, Rio de Janeiro, RJ, Brazil \\ ${ }^{\mathrm{c}}$ Departamento de Engenharia Metalúrgica e de Materiais, \\ Universidade Federal do Rio de Janeiro - UFRJ, CP 68505, \\ CEP 21945-970, Rio de Janeiro, RJ, Brazil
}

Received: September 29, 2010; Revised: June 21, 2011

\begin{abstract}
Industry has been challenged to provide riser systems which are more cost effective and which can fill the technology gaps with respect to water depth, riser diameter and high temperatures left open by flexibles, steel catenary risers (SCRs) and hybrid risers. Composite materials present advantages over conventional steel risers because composite materials are lighter, more fatigue and corrosion resistant, better thermal insulators and can be designed for improving the structural and mechanical response. This paper contains a study of the toughening mechanism of an epoxy resin under rubber addition by means of fractographic analysis and its relation with the fracture process and increase of strength of a composite riser employing this polymeric matrix. Initially, an epoxy resin system was toughened by rubber CTBN addition (10 wt. (\%)) as a way of improving the flexibility of future risers. Mechanical and thermal analyses were carried out for characterizing the polymeric systems. Later, composite tubes were prepared and mechanically characterized. The influence of matrix toughening on the mechanical behavior of the tubes was also studied. Split-disk tests were used to determine the hoop tensile strength of these specimens. The results indicate that the matrix plays an important role in composite fracture processes. The adding rubber to the polymeric matrix promoted a simultaneous increase of stress and elongation at fracture of the tubes manufactured herein, which is not often reported. These results, probably, is function of better adhesion between fibers and polymeric matrix observed in the CTBN-modified composite rings, which was evidenced in the fractografic analysis by SEM after the split-disk tests.
\end{abstract}

Keywords: composite risers, epoxy resin, carboxyl terminated butadiene acrylonitrile (CTBN), mechanical properties, split-disk test

\section{Introduction}

As exploration and production of oil and gas move into deeper water, weight, cost and reliability of water-depth sensitive systems, such as risers become increasingly more important. Composite materials offer some attractive attributes for the offshore service, such as: high specific strength, high corrosion resistance, high thermal insulation, excellent fatigue performance and specific stiffness ${ }^{1}$.

Although development of composite risers began 30 years ago, few works present the results these studies. It is known that in 1979, the Institut Français du Pétrole (IFP) and Aerospatiale began a development of high performance composite tubes for offshore oil industry applications. In 1985, it was launched the Joint Industry Program (JIP) to qualify high performance composites tubes, made of carbon and glass fibers and resin, for use as production risers. The program covered the design, fabrication and testing, and demonstrated that it is possible to manufacture high performance composite tubes ${ }^{2}$. Other works ${ }^{3-6}$ also have shown the feasibility of composite risers.

In order to utilize the full potential of composite materials, the performance evaluation of neat resins is important, as the resins are responsible for the majority of the degradative process that eventually causes the composite failures ${ }^{7}$.
Epoxy resins are considered as one of the most important class of thermosetting polymers and find extensive use in various fields. However, these materials are rather brittle and, for this reason, their toughening has been extensively studied in the last decades ${ }^{8}$. Rubbers are generally well known to affect the mechanical properties of thermoset polymers ${ }^{8}$. The most popular rubbery modifying agent is carboxyl-terminated butadiene-acrylonitrile random copolymer (CTBN) because of its miscibility with the epoxy-hardener mixture during the initial polymerization ${ }^{9}$. The aim, when attempting to toughen brittle polymers, is to increase their toughness without significantly decreasing other properties such as glass transition temperature $\left(\mathrm{T}_{\mathrm{g}}\right)$.

The main objective of modifying the resin system with toughening agent is to increase elongation at fracture, for polymeric matrices used to manufacture composite tubes for riser application. Pipes can be subjected to very large plastic deformation up to $3 \%{ }^{[10]}$ in many situations, such as pipe laying operation (reeling).

This manuscript contains a study of the toughening mechanism of an epoxy resin under rubber addition by means of a fractographic analysis, and its relation with the fracture process composite tubes 
employing this polymeric matrix by determining the hoop tensile strength of these specimens. Split-disk tests were used to determine the hoop tensile strength. These tests present lower cost than hydrostatical tests, and are very efficient to determine the performance of tubular structures which are usually used under internal pressure developing high hoop.

\section{Experimental}

\subsection{Materials}

The polymeric system used in this study was a hot curing epoxy system based on Araldite ${ }^{\circledR}$ LY556 epoxy/Aradur 917 hardener/ Accelerator DY 070 from Huntsman Company. The Araldite ${ }^{\circledR}$ LY 1556 is a diglycidyl ether of bisphenol-A- based epoxy resin with an epoxide equivalent weight of 5.45 eq. $\mathrm{kg}^{-1}$ and viscosity 10000-12000 mPa.s at $25{ }^{\circ} \mathrm{C}$. The Aradur 917 is an anhydride hardener and the accelerator DY 070 is an imidazole accelerator with viscosity 50-100 $\mathrm{mPa}$.s and $50 \mathrm{mPa} . \mathrm{s}$ at $25^{\circ} \mathrm{C}$, respectively.

The elastomer used as rubber modifier was CTBN copolymer supplied by Aldrich Chemicals with acrylonitrile content of $18 \%$ and molecular weight of $3600 \mathrm{~g} \cdot \mathrm{mol}^{-1}$.

The reinforcing element used was glass fiber type-S2 675 tex, 721B ZenTron ${ }^{\circledR}$, from Owens-Corning Fiberglass.

\subsection{Specimen preparation}

\subsubsection{Polymeric samples}

Samples containing 0 and $10 \mathrm{phr}$ CTBN were prepared, which are termed neat and CTBN-modified resins, respectively. In case of blend, initially the epoxy resin was mixed with CTBN, and stirred thoroughly at a temperature of about $60{ }^{\circ} \mathrm{C}$ followed by degassing under vacuum (this procedure allows a pre-reaction between epoxy resin and CTBN to occur prior to addition of hardener). Later, the polymeric system was prepared by mixture resin/CTBN or neat resin with accelerator (2 wt. (\%)), followed by addition of the hardener (90 wt. (\%)) for at least 5 minutes. The resultant homogeneous mixture was poured into a steel mold, whose surface was treated with a release agent, and cured into oven for 4 hours at $80^{\circ} \mathrm{C}$ and then post cured for 4 hours at $120^{\circ} \mathrm{C}$, as indicated by the manufacturer. The specimens' dimensions to tensile tests followed the ISO 527-2 standard.

\subsubsection{Composite tubes}

Tubes were manufactured using a filament winding process, in which the reinforcing fibers are impregnated with the polymeric systems, i.e., neat and CTBN-modified resins, and applied to a $101.6 \mathrm{~mm}$ diameter rotating steel mandrel in precise orientation angles. To be consistent with the notation used for the polymeric systems, the tubes are called neat and CTBN-modified. A filamentwinding machine from Tecservice (São José dos Campos, Brazil) was used. The angle-ply tubes consisted of eight layers with a lamination of $\left[88^{\circ}{ }_{2} / \pm 55^{\circ} / 88^{\circ}{ }_{2}\right]$ configuration. The fiber volume fraction was around $0.41( \pm 0.04)$ for both systems. The tube length, internal diameter and thickness were 1800, 101.6 and $5.6 \mathrm{~mm}$, respectively. After 30 minutes of spinning, these wound tubes together with the mandrel were placed into a temperature controlled oven for the curing operation. After curing, the composite tubes were removed from their mandrels. Figure 1 shows the steps for manufacturing tubes.

Initially, to help taking composite tube out, the mandrel surface was treated with a release agent and coated with a layer of teflon sheet. Mandrel then was coated with a polyester fabric to improve the internal surface of composite tube. As described above, the tubes were made of two internal circumferential layers $\left(88^{\circ}\right)$, followed by four helical layers at $55^{\circ}$ and two external circumferential layers. Finally, after the molding process, the mandrel was put inside an oven and kept turning during the curing process.

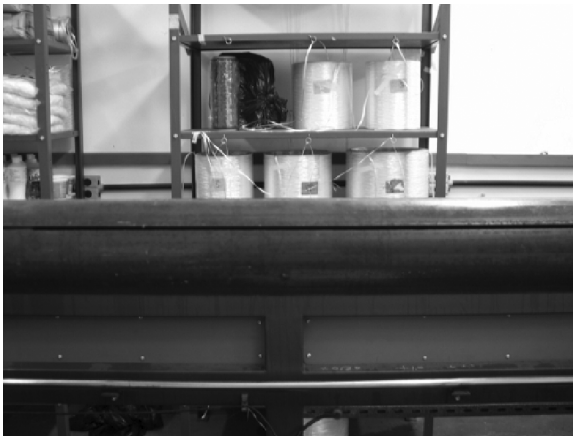

Mandrel with release agent

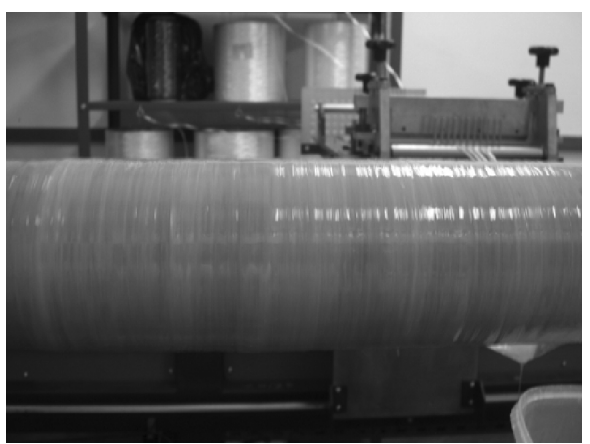

Layers at $88^{\circ}$

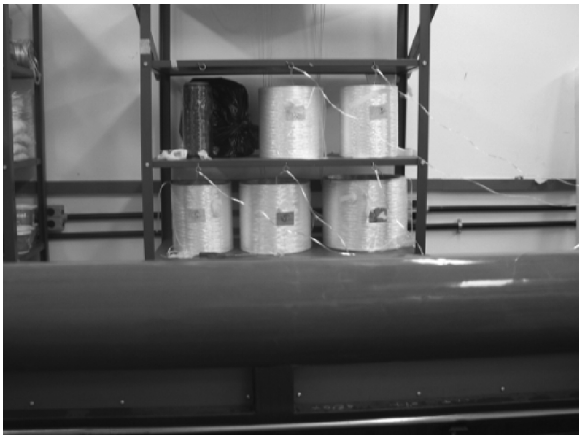

Teflon sheet

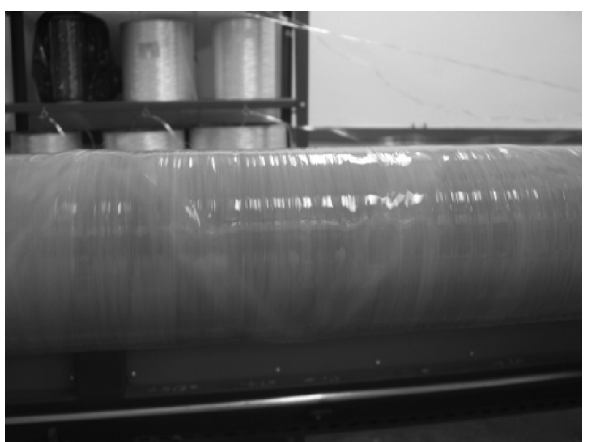

Layers at $\pm 55^{\circ}$

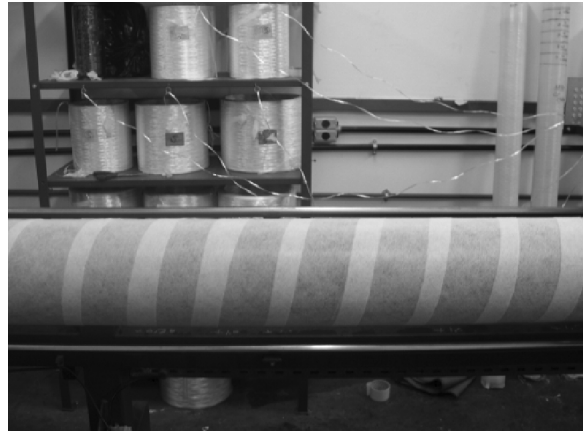

Polyester fabric

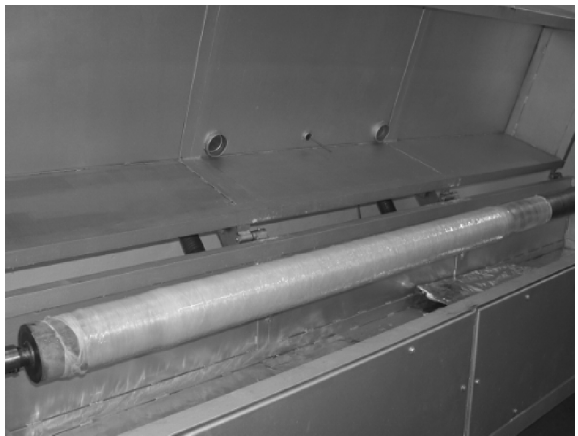

Tube in oven

Figure 1. Stages of tube production. 


\subsection{Analysis}

\subsubsection{Polymeric samples}

\subsubsection{Mechanical analysis}

Tensile tests of the polymeric samples, with and without CTBN, were carried out at room temperature using an EMIC testing machine, model DL 10000 , with a load cell of $5 \mathrm{kN}$, extensometer model G-51-12-A, and loading speed of $1.0 \mathrm{~mm} / \mathrm{min}$, according to ISO 527-2. The extensometer was located at the center of specimens with gage length of $23.6 \mathrm{~mm}$. The tensile strength, elasticity modulus, strain-to-failure and fracture toughness values were obtained. Fracture toughness was measured from the area under the stress vs. strain curve of the tensile tests. The values were taken from an average of six specimens.

\subsubsection{Fractographic analysis}

Fractured surfaces obtained from mechanical tests were examined at different magnification by using JEOL JSM-6460LV scanning electron microscope (SEM) in order to observe the fracture behavior of the specimens, the rubber domains dispersed in the matrix, and the interaction of these domains with the epoxy matrix. Specimen surfaces were coated with a thin layer of gold by sputtering to provide a conductive surface.

\subsubsection{Fourier transform infrared spectroscopic (FTIR) spectroscopy}

The cured polymeric system epoxy/CTBN was ground to a fine powder, mixed with potassium bromide $(\mathrm{KBr})$ powder and pressed into a pellet. For the liquid sample, CTBN, sodium chloride $(\mathrm{NaCl})$ pellets were used. FTIR were recorded using Spectrum One Spectrophotometer from Perkin-Elmer in the wavelength range of $4000-500 \mathrm{~cm}^{-1}$, at a resolution of $4 \mathrm{~cm}^{-1}$ using 32 scans.

\subsubsection{Thermal analysis}

Differential Scanning Calorimeter (DSC) thermograms were obtained using a DSC, Diamond from Perkim-Elmer. Two scans were made from 40 to $200{ }^{\circ} \mathrm{C}$, with a heating rate of $10{ }^{\circ} \mathrm{C} / \mathrm{min}$, followed by a fast cooling $\left(300{ }^{\circ} \mathrm{C} / \mathrm{min}\right)$ and reheating at the same heating rate. All tests were conducted in nitrogen atmosphere at $20 \mathrm{~mL} / \mathrm{min}$.

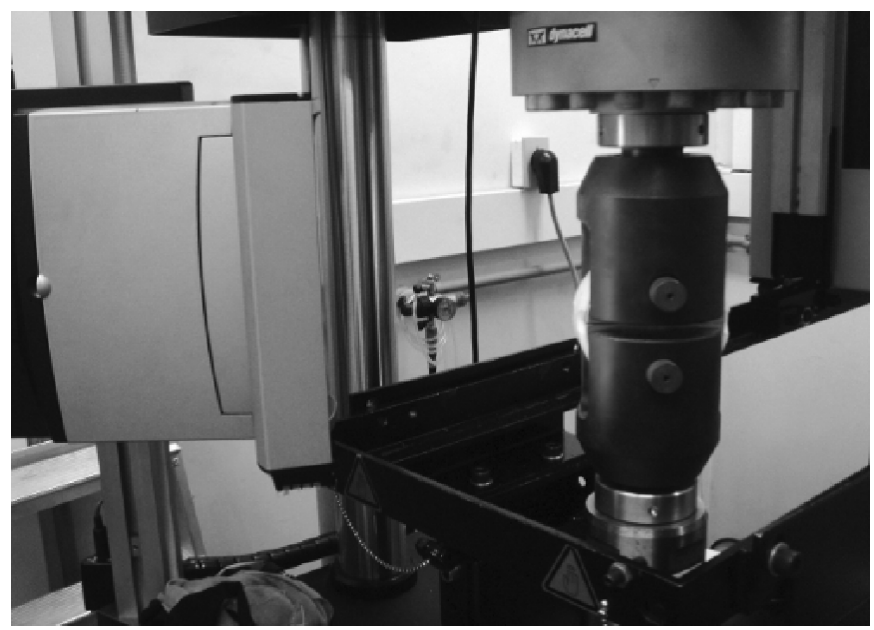

(a)

\subsubsection{Dynamic mechanical thermal analysis}

The viscoelastic properties of the modified epoxy as well as the neat resin were measured using a DTMA 7e, from Perkim-Elmer. All samples were tested using a sample size of $(22 \times 6 \times 2 \mathrm{~mm})$ under a 3 -point bend. The measurements were carried out at a heating rate of $30{ }^{\circ} \mathrm{C} / \mathrm{min}$ from 0 to $200{ }^{\circ} \mathrm{C}$, at a fixed frequency level of $1 \mathrm{~Hz}$, with static and dynamic forces of 330 and $300 \mathrm{mN}$, respectively.

\subsubsection{Thermogravimetric analysis (TGA)}

Thermogravimetric analysis was performed with a TGA Pyris 1 from Perkin-Elmer to investigate the thermal resistance of the neat and rubber-modified resins. The TGA cell was purged with nitrogen at $20 \mathrm{~mL} / \mathrm{min}$ during degradation runs. The analyses were carried out with approximately 5-10 $\mathrm{mg}$ of sample in a platinum sample pan. The heating rate in each run was kept at $10^{\circ} \mathrm{C} / \mathrm{min}$, from 0 to $700{ }^{\circ} \mathrm{C}$.

\subsubsection{Composite samples}

\subsubsection{Split-disk tests}

Split-disk test specimens were produced by cutting composite tubes. The cutting of specimens and the determination of apparent hoop tensile strength were performed according to ASTM D-2290.

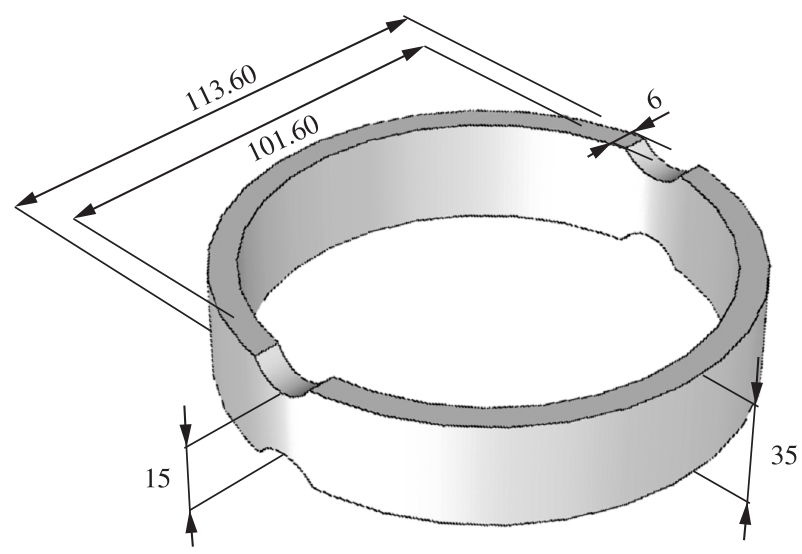

Figure 2. Schematic of the split-disk-tests specimens. All dimensions are in millimeters.

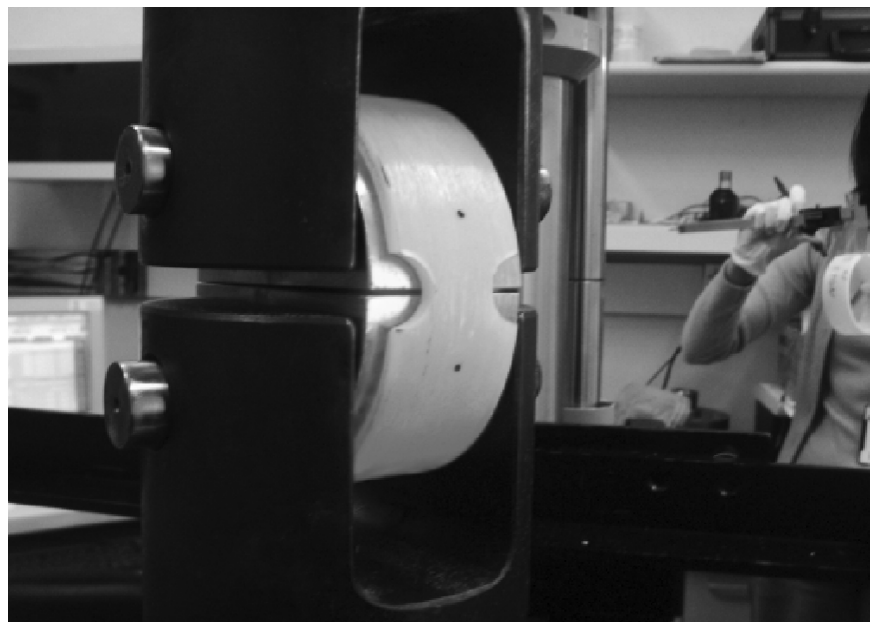

(b)

Figure 3. Split-disk test: a) side, and b) front view. 
Specimen geometry and dimensions are shown in Figure 2. The testing machine used was a Shimadzu UHF hydraulic machine with a loading capacity of $1000 \mathrm{kN}$, video extensometer, and crosshead rate of $5 \mathrm{~mm} / \mathrm{min}$. The tests (Figure 3 ) were performed at room temperature.

\subsubsection{Fractographic analysis}

Similar to polymeric samples, fractured surfaces obtained from mechanical split-disk test were examined at different magnification by using JEOL JSM-6460LV scanning electron microscope (SEM) in order to observe the fracture behavior of the specimens. Specimen surfaces were coated with a thin layer of gold by sputtering to provide a conductive surface.

\section{Results and Discussion}

\subsection{Polymeric samples}

\subsubsection{Mechanical analysis}

Figure 4 presents the stress-strain curves for both polymeric systems considered herein.

Brittle fracture, i.e., absence of yielding, is evidenced for the neat epoxy resin, whereas the CTBN-modified epoxy exhibits a ductile deformation with the appearance of an upper yield stress. It can be observed from Figure 4 that CTBN in resin decreased the fracture stress (changed from 76.31 to $66.81 \mathrm{MPa}$ ) and increased the elongation at fracture (changed from 2.96 to 5.24\%). Besides, a yielding is observed in rubber modified sample.

The reduction of the fracture stress of the CTBN-modified resin may be attributed to the lowering in cross-linking density of this polymeric system. The rubber modifier occupies the reaction sites during the curing process. Phase separated rubber domains occupy the regions between the reaction centers, blocking the cross-linking reaction in these centers. Similar observations have been reported by many authors using different rubbers ${ }^{11-16}$.

As expected, the tensile modulus also decreased with addition of CTBN, from 3.45 to $2.75 \mathrm{GPa}$. The decreasing in these properties can be related to stiffness of the polymeric system. Decreasing of the stiffness is, probably, caused by rubber addition which promoted the lowering in cross-linking density. Moreover, the change in the Young's modulus of the blend might be related to the fact that the

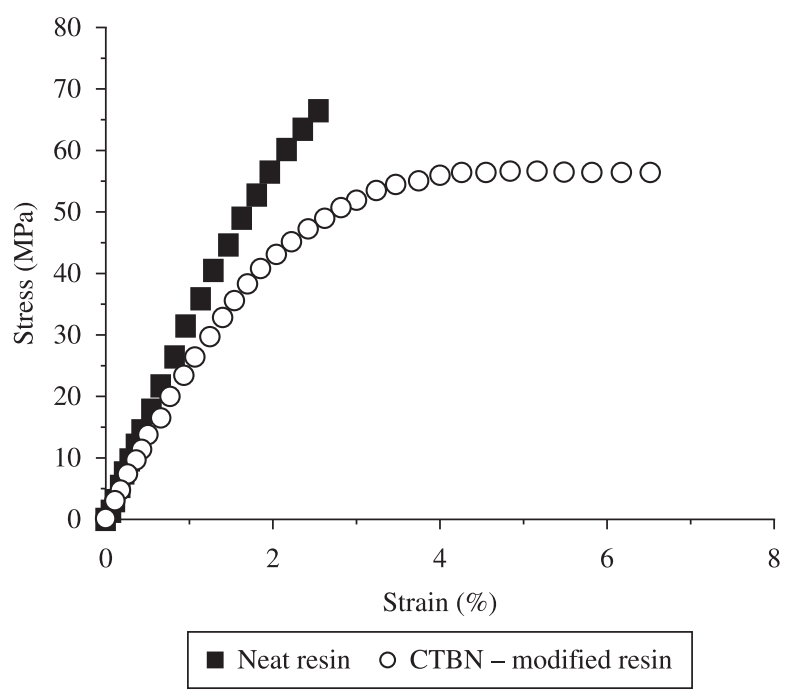

Figure 4. Stress-strain curves of neat resin and 10\% CTBN modified epoxy. modulus of the CTBN is much lower than that of the epoxy phase. The same reasons can explain the increase of the strain and toughness at fracture. It was observed in many studies ${ }^{11-16}$ that the tensile modulus decreases with increasing rubber content.

Furthermore, it is well-known that an increase in elongation at fracture in these polymeric blends can be an indication of a good adhesion by a chemical reaction between rubber and resin, as it was evidenced herein by IR spectroscopy.

Many different mechanisms have been proposed to explain the improvement in the fracture behavior of toughened thermoset. These proposals were based mainly on the phenomena observed in toughened thermoplastics. In 1956, Merz et al. ${ }^{17}$ proposed the first mechanism of ultimate failure for heterogeneous mixtures of polystyrene with styrene butadiene copolymers. The authors proposed that the rubber particles bridge the opening fracture surfaces and, at this moment, the fracture requires the tearing of rubber particles. Other mechanisms, such as rubber particle cavitation ${ }^{11,14,18-20}$, energy absorption through rubber deformation ${ }^{21-23}$ and crack branching, caused by rubber particles ${ }^{24}$, have also been observed in the rubber modified polymers.

For understanding the behavior and mechanism deformation, experimental studies on the rubber modified polymeric systems rely largely on observations of the fracture surfaces by microscopy, including scanning electron microscopy (SEM). In the present study, the SEM analysis was applied to investigate the deformation/ toughening mechanism presented for both polymeric systems considered herein. This analysis is presented in the next section.

\subsubsection{Fractography}

The tensile behaviour of the polymeric systems can be explained in terms of the morphology observed by SEM. The SEM microphotographs for neat and CTBN-modified resin are shown in Figures 5 and 6, respectively.

From the photograph of the neat epoxy specimen, one can see the presence of three distinct regions (Figure 5a), which are considered characteristic of brittle systems: a) an initial region of fracture characterized by a smooth and flat surface, b) a transition region, where the surface roughness steadily increases, and c) the final region of fracture with conical marks ${ }^{25}$. Brittle fracture of thermoset resins is also characterized by the presence of the ripples and cracks in different plane, indicating that there is no energy dissipation mechanism operating ${ }^{14}$. This characteristic was also observed herein (Figure 5c). Similar observations were done by other authors ${ }^{11,26,27}$. The conical marks, normally observed in the final propagation zone, can be better observed in Figure $5 b$ (indicated by dashed lines). Maybe these conic-shaped patterns are the intersection between a moving planar crack front and a radically growing circular craze or secondary crack front ${ }^{28,29}$.

The fracture surfaces of the CTBN-modified resin showed the presence of two-phase, i.e., they revealed rubber particles dispersed in a rigid continuous phase. Usually, the fracture surfaces of the rubber-modified epoxy systems present a rubbery phase dispersed, as particles, in a rigid continuous epoxy matrix. This phase separation initiates in the early stage of polymerization, which the linear molecular chains presenting enough freedom to react with other molecules ${ }^{27,30}$.

As described previously, different mechanisms produce toughening effect in rubber-modified epoxies. Herein, it was observed that the rubber particles were submitted to deformation and partly fractured, as can be seen in the regions indicated by arrows (Figure 6). Kunz et al. ${ }^{31}$ relate that the rubber particles bridging the opening crack surfaces are capable of very large extensions during which elastic energy is stored and later dissipated during tearing of the rubber. 


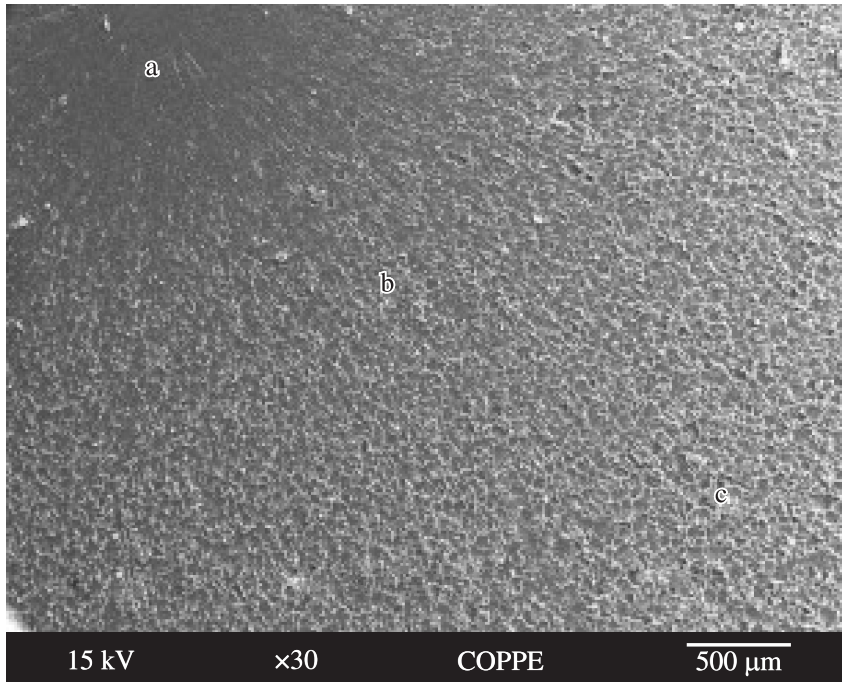

(a)

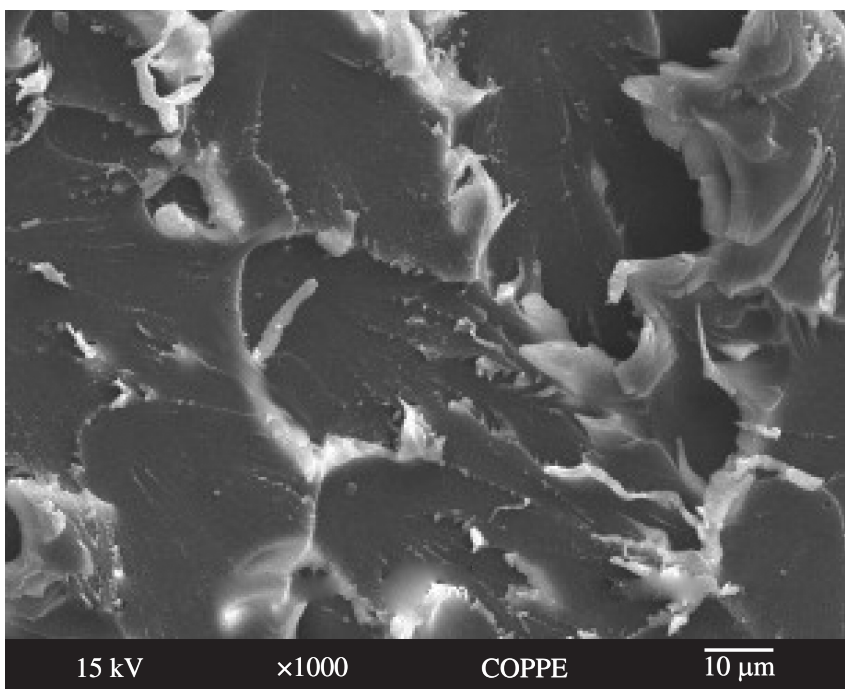

(b)

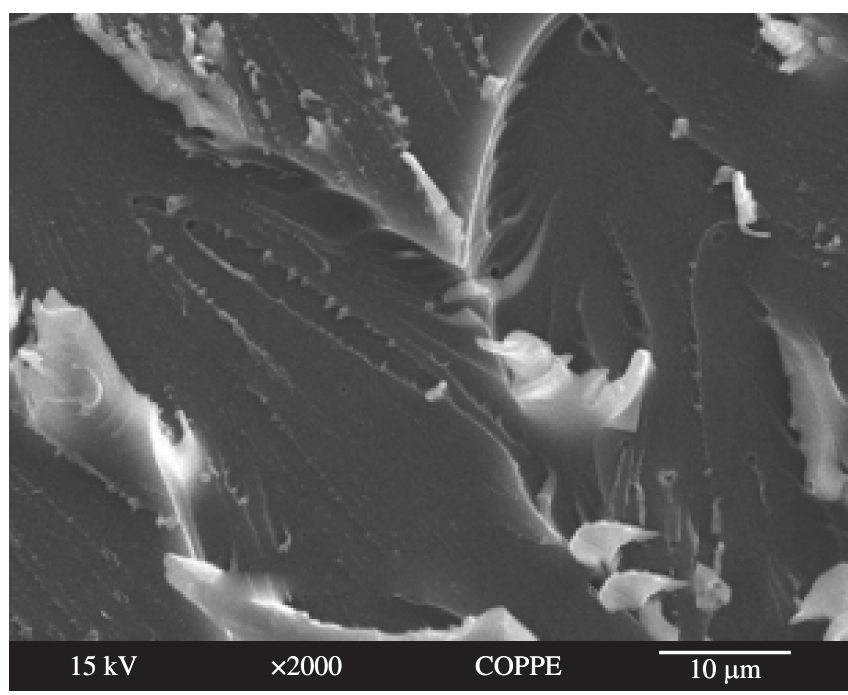

(c)

Figure 5. SEM micrographs of neat resin at magnifications a) $30 \times$, b) $1000 \times$ and c) $2000 x$

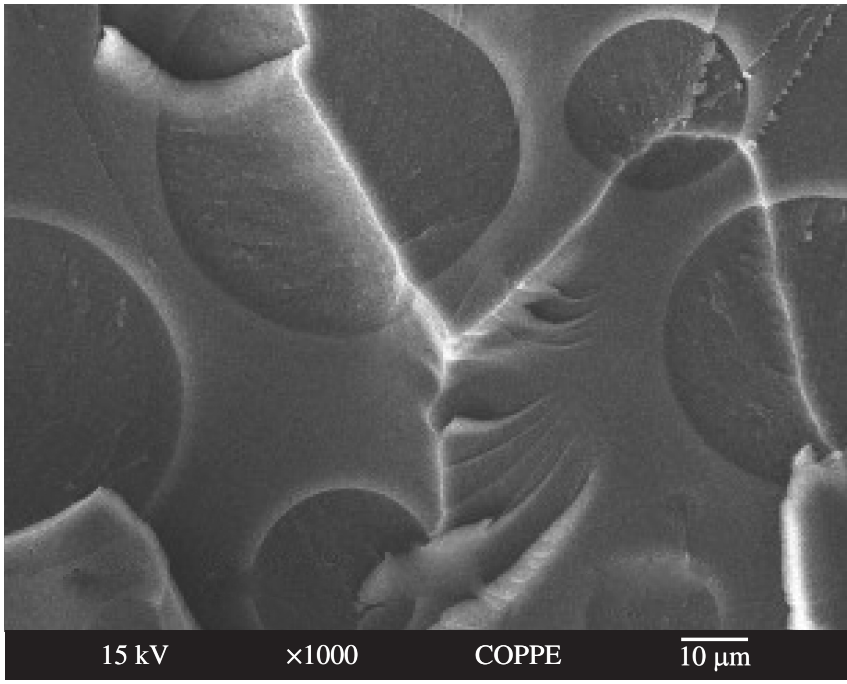

(a)

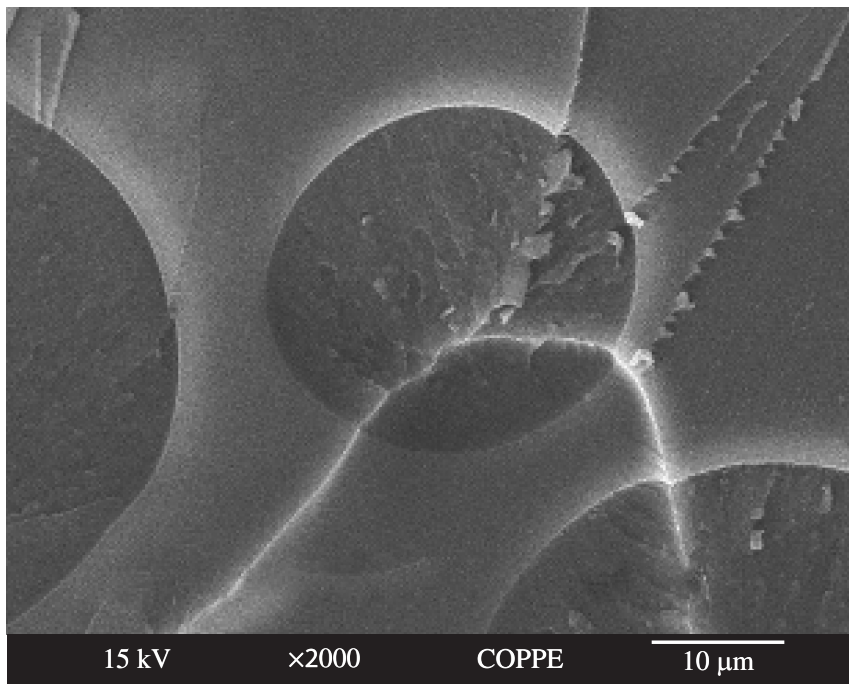

(b)

Figure 6. SEM micrographs of CTBN-modified resin at magnifications a) $1000 x$ and b) $2000 x$

According to these authors ${ }^{21}$, this mechanism is particularly relevant to rubber-modified cross-linked thermosetting polymers.

The micrographs show the crack developed through the rubber particle and also indicate that a good adhesion between particle and matrix has occurred. In fact, it has been reported that an improvement in elongation at fracture/fracture toughness could be an indication of a good adhesion via chemical reaction epoxy-rubber ${ }^{14}$. These results are in accordance with those of tensile properties, where some yield occurred upon addition of CTBN rubber accompanied by an increase in elongation at fracture, and with FTIR spectroscopy analysis, which evidenced the reaction between rubber particles and epoxy matrix.

\subsubsection{Fourier-transform infrared (FTIR) spectroscopy}

FTIR spectrums of CTBN and CTBN-modified resin, showed in Figure 7, have been obtained in an attempt to elucidate the occurrence of any chemical reaction between epoxy resin and CTBN. These results indicate the formation of the links as shown in Figure 8, reaction between epoxy groups of DGEBA and $\mathrm{COOH}$ groups of CTBN. 


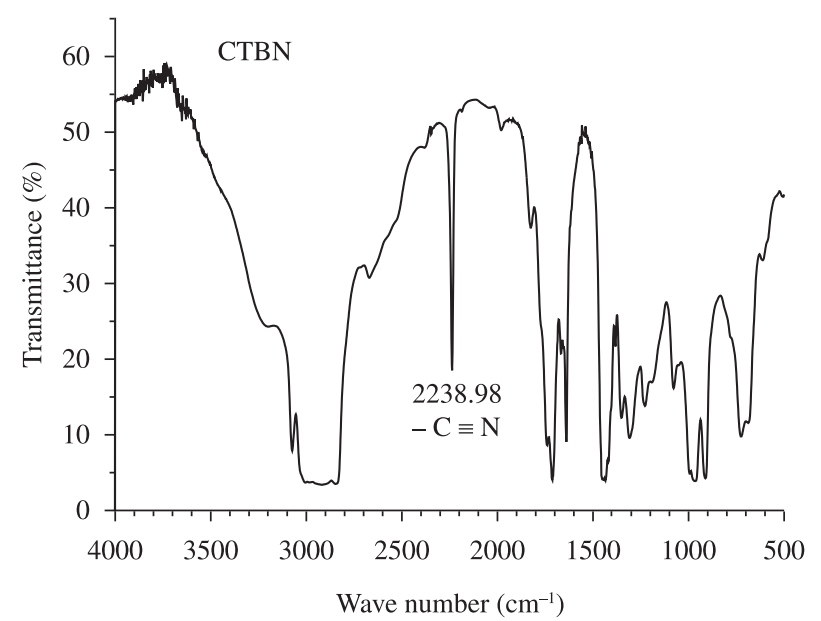

(a)

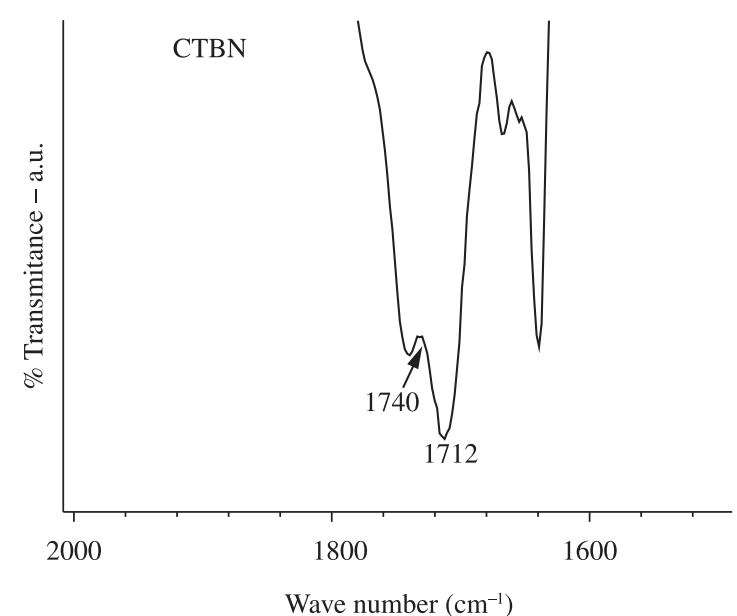

(c)

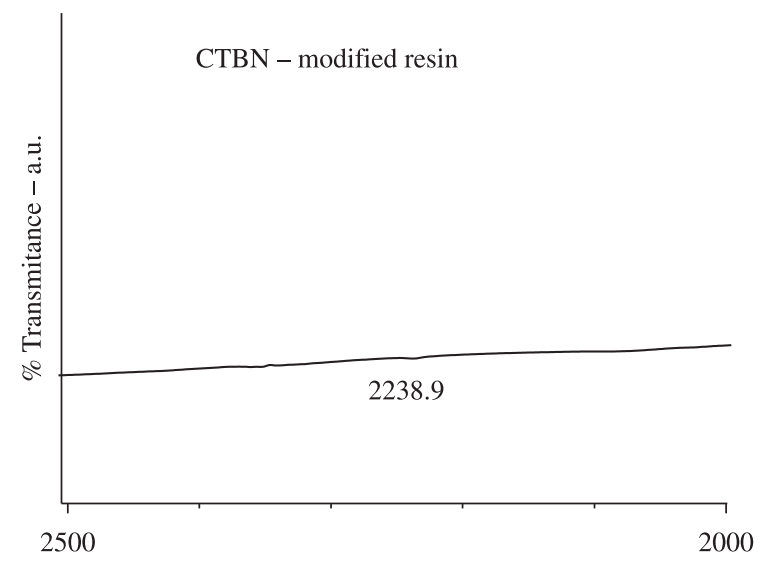

Wave number $\left(\mathrm{cm}^{-1}\right)$

(e)

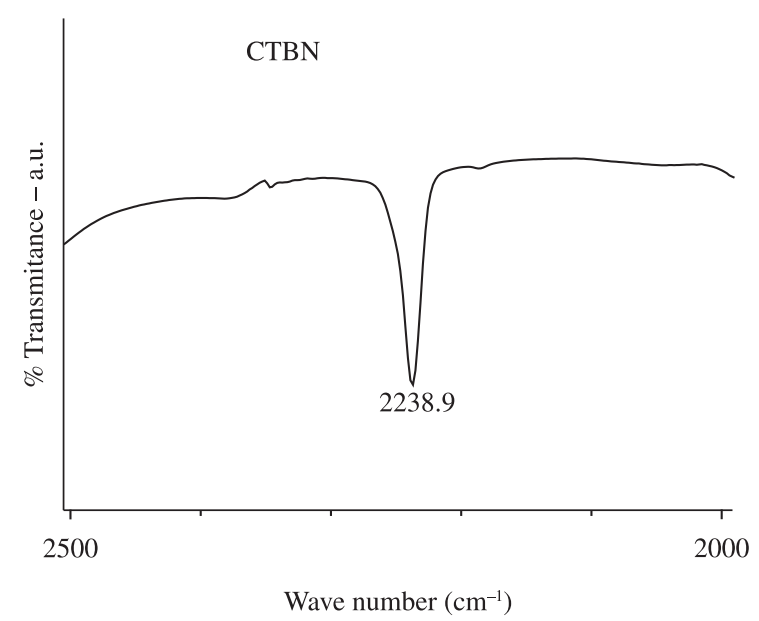

(b)

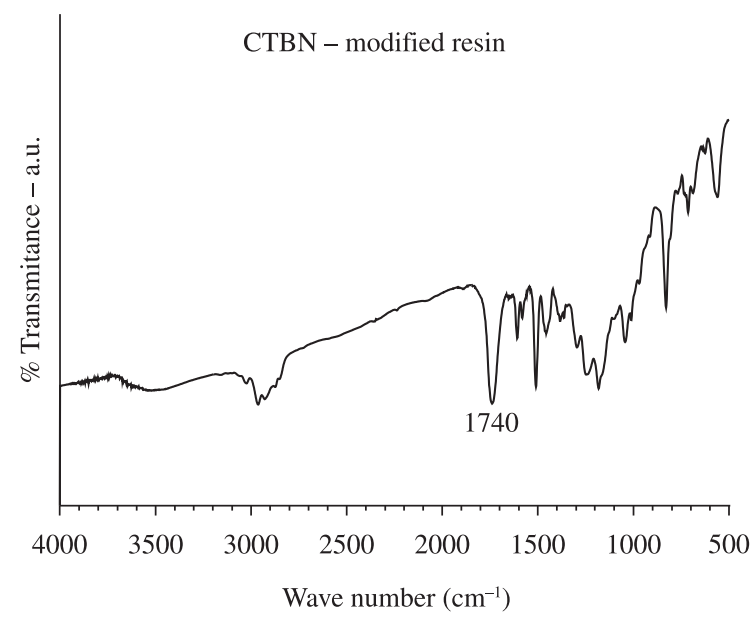

(d)

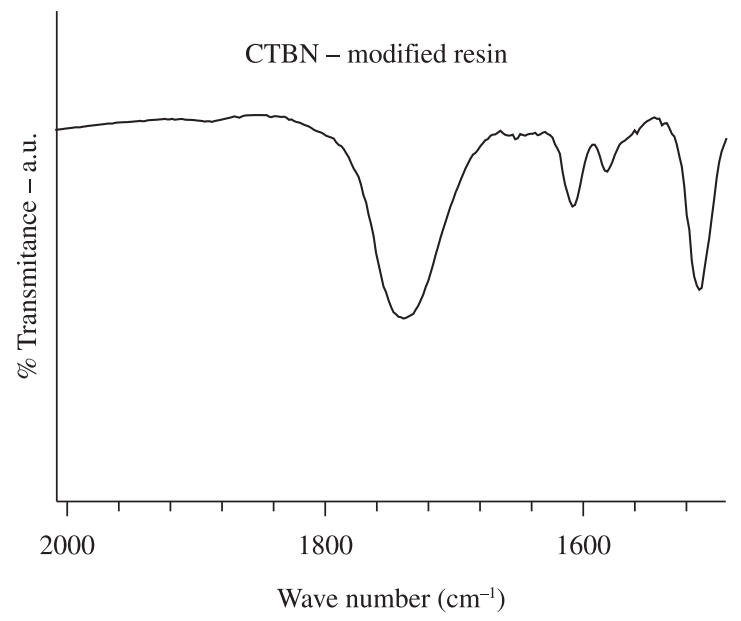

(f)

Figure 7. FTIR spectrums of CTBN (a, b and c) and CTBN-modified resin (d, e and f). Figures (a) and (d) are the complete IR spectrum. Figures (b), (e), (c) and (f) are the magnification of IR spectrum of 2239 and $1740 \mathrm{~cm}^{-1}$ regions, respectively. 
<smiles>CC(C)(CC(O)COc1ccc(C(C)(C)c2ccc(OC(C)(C)C3CO3)cc2)cc1)Oc1ccc(C(C)(C)c2ccc(C3CO3)cc2)cc1</smiles>

DGEBA

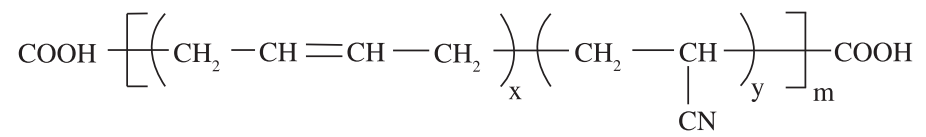

CTBN<smiles>CCC(C)(CC1CO1)c1ccc(C(C)(C)c2ccc(OC)cc2)cc1</smiles><smiles>CC(O)CCOc1ccc(C(C)(C)c2ccc(Cl)cc2)cc1</smiles><smiles>CC(=O)OCC(O)C=O</smiles><smiles>CCC(CC)(CC1CO1)Oc1ccc(C(C)(C)c2ccccc2)cc1</smiles><smiles>CC(C)Oc1ccc(C(C)C(C)C(C)O)cc1</smiles><smiles>CC(=O)OCC(C)O</smiles>

Figure 8. Scheme showing the reaction between epoxy groups of DGEBA and COOH groups of CTBN: formation of functional group esther.

The transmittance band at $2239 \mathrm{~cm}^{-1}$ presented in the spectrum of CTBN (Figure 7a), which can be ascribed to the nitrile group of CTBN, was not observed in the cured blend system (Figure 7b). Band at $1712 \mathrm{~cm}^{-1}$, which can be ascribed to the carboxylic group of CTBN, was also not observed in the FTIR spectrum. On the other hand, it was observed a new stretched peak at $1740 \mathrm{~cm}^{-1}$ that may indicate the formation of the ester functional group. These facts can be considered as a clear indication of the reaction between CTBN and epoxy resin. Previous works on CTBN-modified epoxies support this observation ${ }^{13,31,32}$.

\subsubsection{Differential scanning calorimetry}

The purpose this analysis was just to allow the observation of any type of thermal process during heating scan in the DSC. Exothermic peaks are related to the cure process, i.e., these peaks are related with the energy involved in the cross-linking reaction of the resin ${ }^{33}$. Thus, to produce stable polymeric systems, without residual exothermic reactions, a suitable cure treatment is necessary.
As shown in Figure 9, neither of samples presented profile characteristic of exothermic reaction, indicating the complete cure of the systems. These results confirm that the cure cycle by the manufacturer was enough to ensure the whole cure of both polymeric systems (neat resin and CTBN-modified resin), as there was no heat liberated during runs.

\subsubsection{Dynamic mechanical analysis}

In the present work, a dynamic mechanical analyzer (DMA) was used to measure the glass transition temperature, taken as the maximum of the $\tan \delta$ curve, of the polymeric systems and evaluate the loss and storage modulus as a function of rubber addition in the epoxy resin. Figure 10a-c shows the DMA data for neat and CTBN-modified resin. The plot consisting of storage modulus ( $\mathrm{E}^{\prime}$ ) of the samples as a function of temperature has been shown in Figure 10a. In both cases, the values of $E^{\prime}$ decreased with increasing temperature. The storage modulus decreased with increasing temperature indicating that the network passed from a stiff hard to a soft and flexible material. 


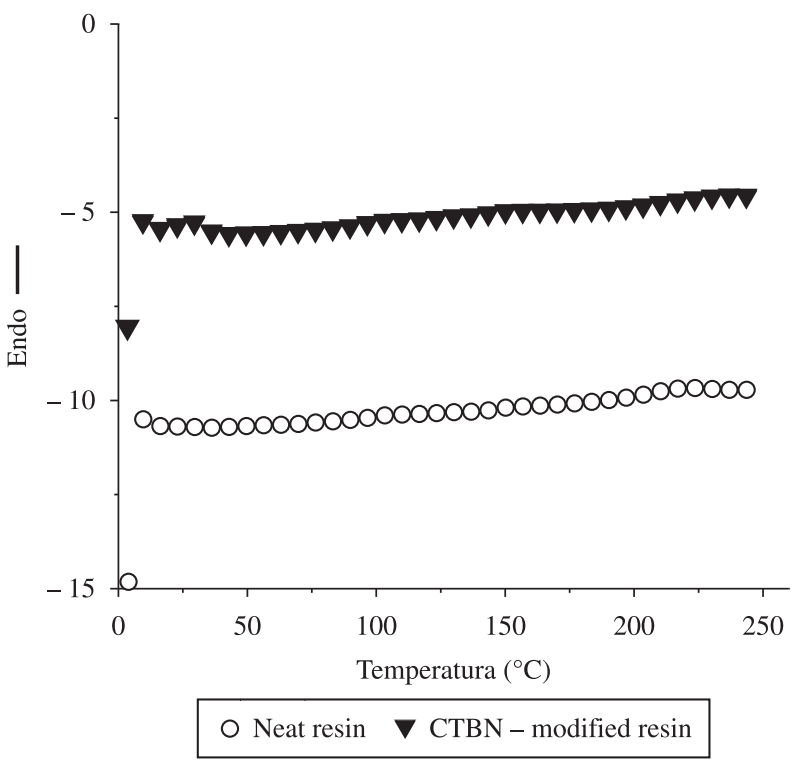

Figure 9. DSC thermograms of specimens: neat resin and CTBN modified resin.

Besides, at any given temperature, the storage modulus decreased with rubber addition which could be attributed to the incorporation of a low modulus rubber into the epoxy matrix and to a reduction in the cross-linking density of the polymeric system. A similar reasoning was given by other authors ${ }^{13,14,27,34}$.

The addition of CTBN in the resin decreased the $\mathrm{T}_{\mathrm{g}}$ of the matrix phase by about $5^{\circ} \mathrm{C}$, Figure $10 \mathrm{~b}$. This difference is directly related with the difference in the crosslink density of the systems ${ }^{35}$. Rubber modifier occupies the reaction centers during the curing process lowering the cross-linking density of the epoxy system ${ }^{36}$.

Figure 10c represents the loss modulus, E", vs. temperature for neat and CTBN-modified resin. The transition peak becomes more intense by the cross-linking ${ }^{27}$. With rubber addition, the peak shifts to a lower temperature. This is attributed to the dissolution of CTBN into the polymeric network. Previous works on rubber-modified epoxy support this observation ${ }^{11,13-16,27,34}$.

\subsubsection{Thermogravimetric analysis}

The thermal stability and thermal degradation patterns of the polymeric systems were revealed by TGA. Figure 11 shows TGA thermograms of neat and CTBN-modified resin. A two-stage weightloss behavior was observed for both samples. It can be observed that the short stage of degradation for neat and modified resin occurred around 245 and $235{ }^{\circ} \mathrm{C}$, respectively, with an approximately $7 \%$ weight loss. This fact is attributed to the presence of impurities ${ }^{11,37}$. In both polymeric systems, the main degradation takes place above $390{ }^{\circ} \mathrm{C}$, owing to the thermal degradation of epoxy network. It can be confirmed that the stability of the blends is little decreased with increasing rubber content, as can be seen in Figure 11, which is attributed to the reduced cross-linking density of the epoxy network ${ }^{38}$.

\subsection{Composite tubes}

\subsubsection{Split-disk tests}

In order to characterize the effect of the addition of rubber CTBN on the hoop tensile properties, split-disk tests were carried out in samples of both composite tubes (CTBN-modified and unmodified

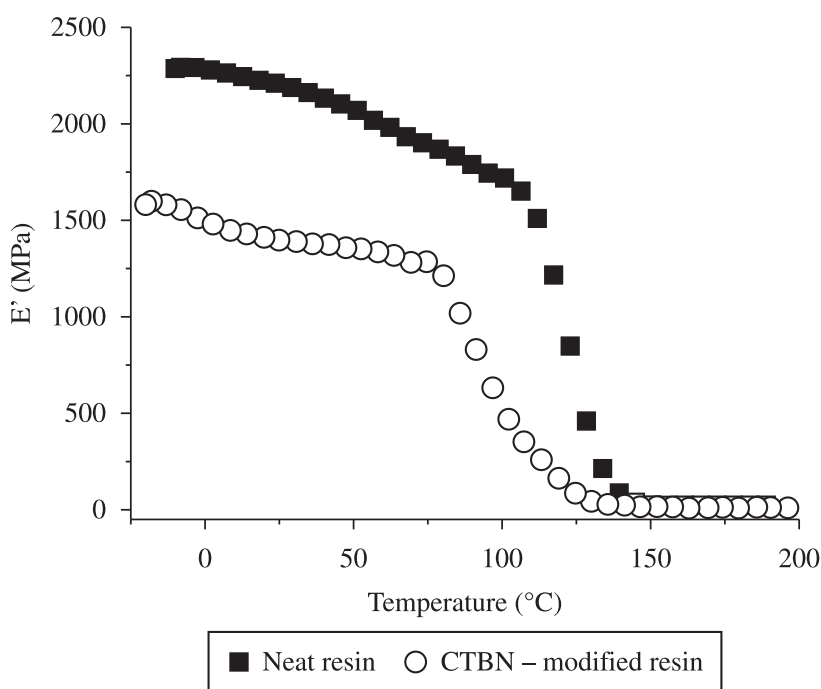

(a)

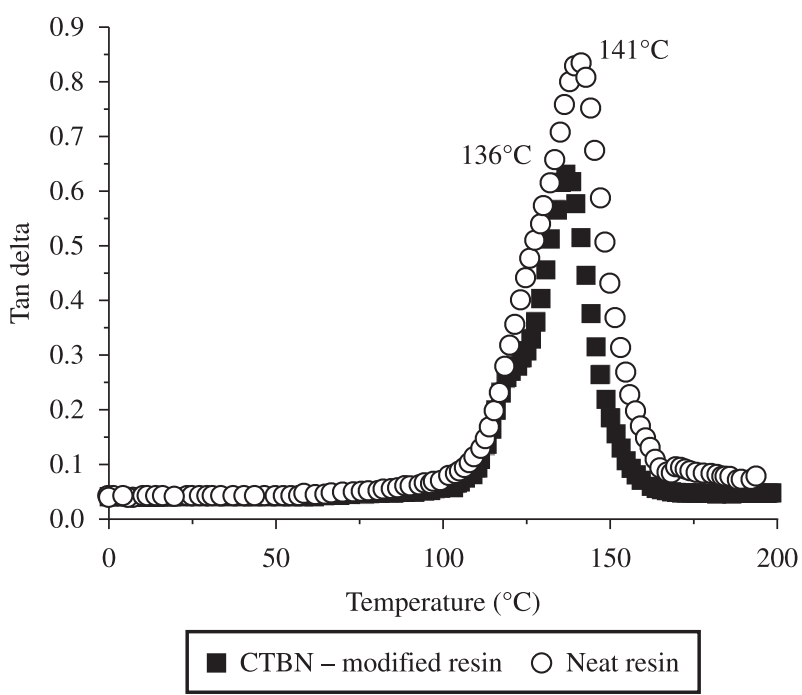

(b)

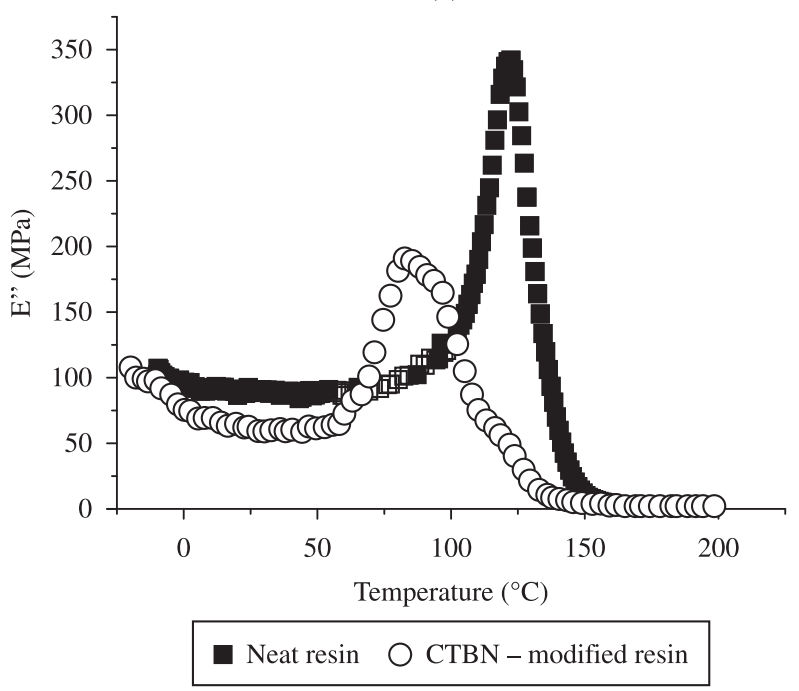

(c)

Figure 10. DMA plots showing the behavior of neat and CTBN-modified resin: a) storage modulus, b) values of $\tan \delta$ and c) of loss modulus with temperature. 
polymeric matrix). Besides obtaining the hoop tensile properties of the specimens, failure types and their locations were also investigated. The hoop tensile strength vs. strain curves are shown in Figure 12.

It was observed that the CTBN-modified ring specimens presented hoop tensile strength and strain values higher than unmodified specimens. Replacing the brittle epoxy matrix with a ductile one influenced the other tensile properties of composites. The tensile strength presented an increase of approximately $14 \%$ with rubber addition into polymeric matrix. Fracture stress changed from 731.00 to $831.31 \mathrm{MPa}$. Rubber addition to thermoset resins is known to lead to significant increases in crack-growth resistance ${ }^{39-41}$. Besides, the CTBN-modified specimens also presented higher strain at fracture values than unmodified samples on split-disk test, an increase of approximately $32 \%$. To clarify this behavior, we examined the macroscopic and microscopic fracture profiles after the tests. Figures 13 and 14 show the macroscopic fracture appearances of the specimens. From these photographs it can be verified the dominant

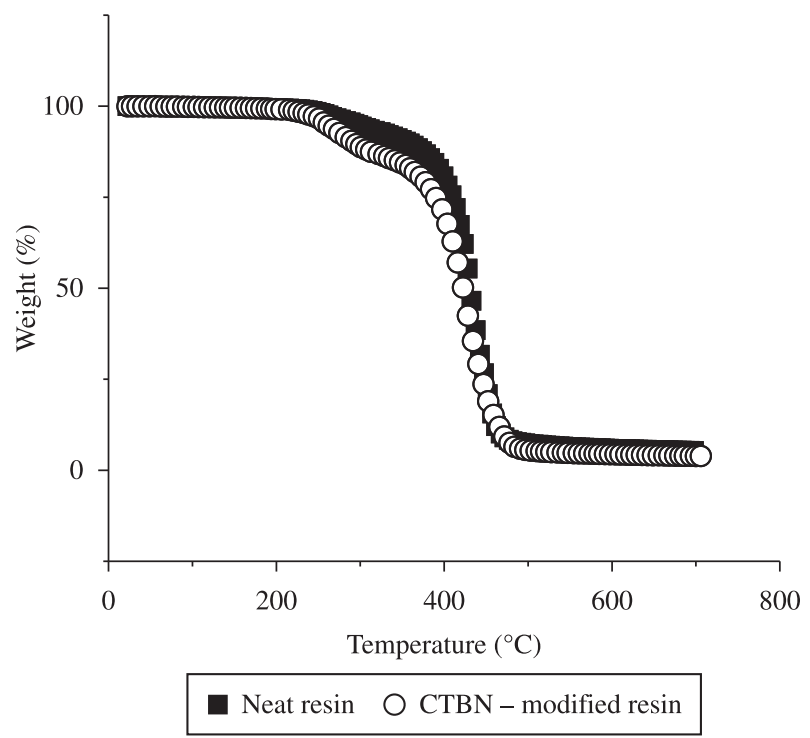

Figure 11. TGA thermograms of neat and CTBN-modified resin.

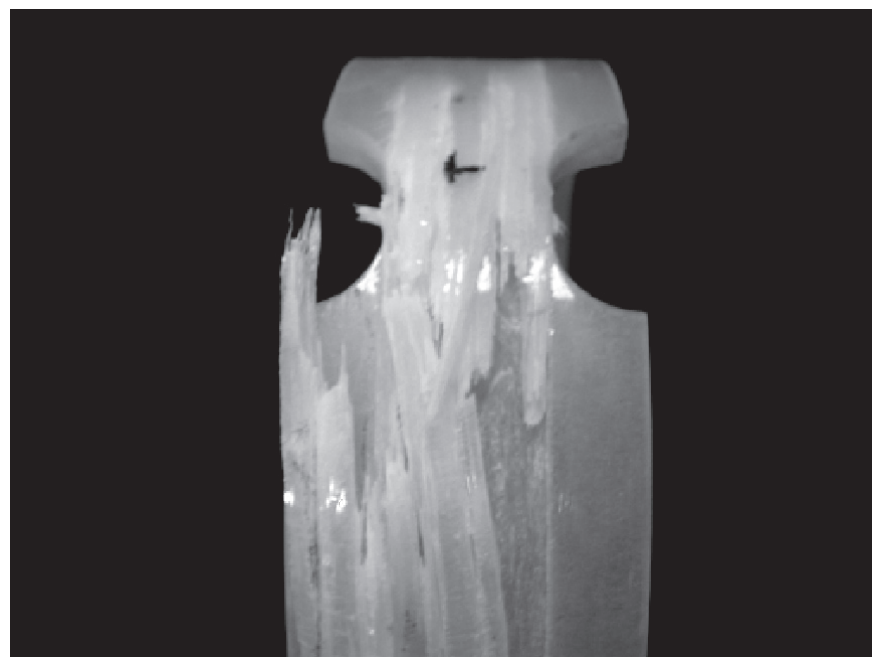

(a) failure mechanisms presented during the test. For all samples the fracture occurred in the reduced section. For layers having $88^{\circ}$ winding angle, fiber-matrix debonding parallel to the fibers was followed by a fiber fracture in all samples of both ring groups (neat and modified-CTBN). For $\pm 55^{\circ}$ filament winding layers, fiber-matrix debonding and delamination were observed. Similar results were observed by Kaynak and his coworkers ${ }^{42}$ which investigated the effect of different winding angle on mechanical performance of specimens under split-disk tests.

In the neat rings (Figure 13), can be observed more clearly the separation between the laminas, regions of delamination, where the fracture of fibers occurs in blocks. On the other hand, in the rubbermodified specimens (Figure 14) delamination regions were not well determinate. In these samples, the fibers presented themselves quite loose in the fracture region, making difficult the observation of delamination. It is a known fact that the interlaminar crack propagation (delamination) is the most commonly observed failure

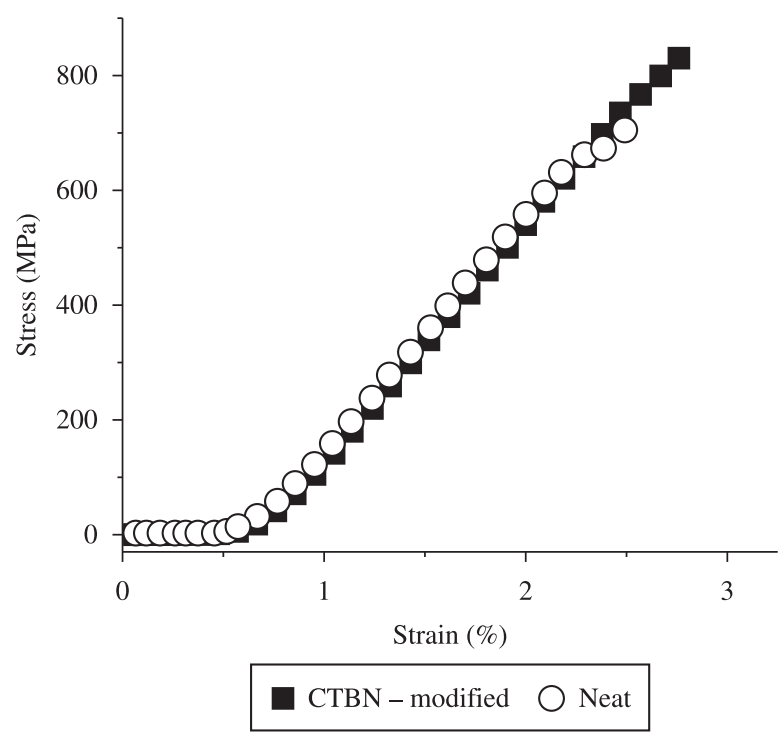

Figure 12. Hoop tensile strength vs. dislocation curves for rings of both composite tubes (CTBN modified and unmodified polymeric matrix).

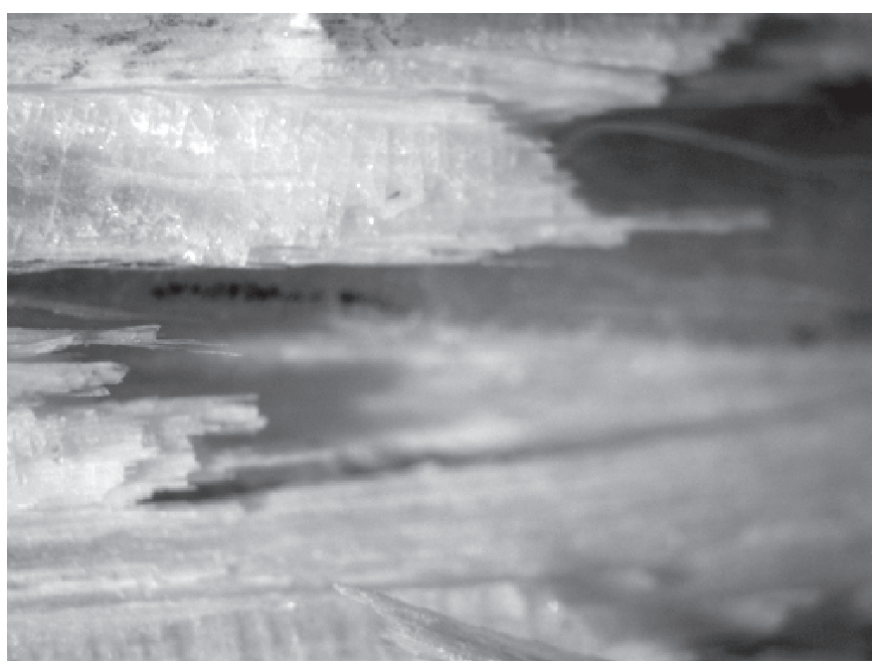

(b)

Figure 13. Macroscopic fracture appearances of neat rings: a) fracture region and b) composite layers at fracture region. 


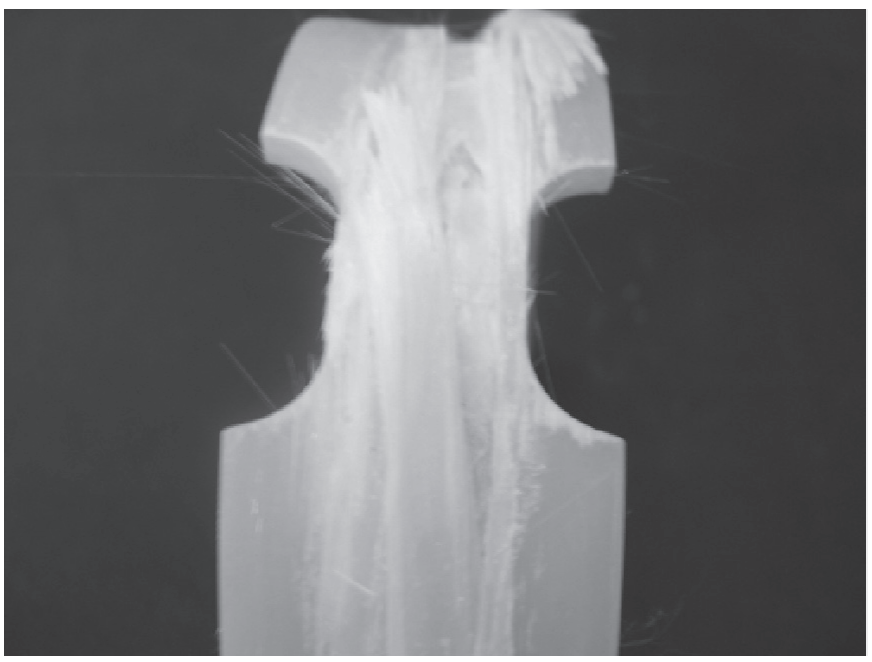

(a)

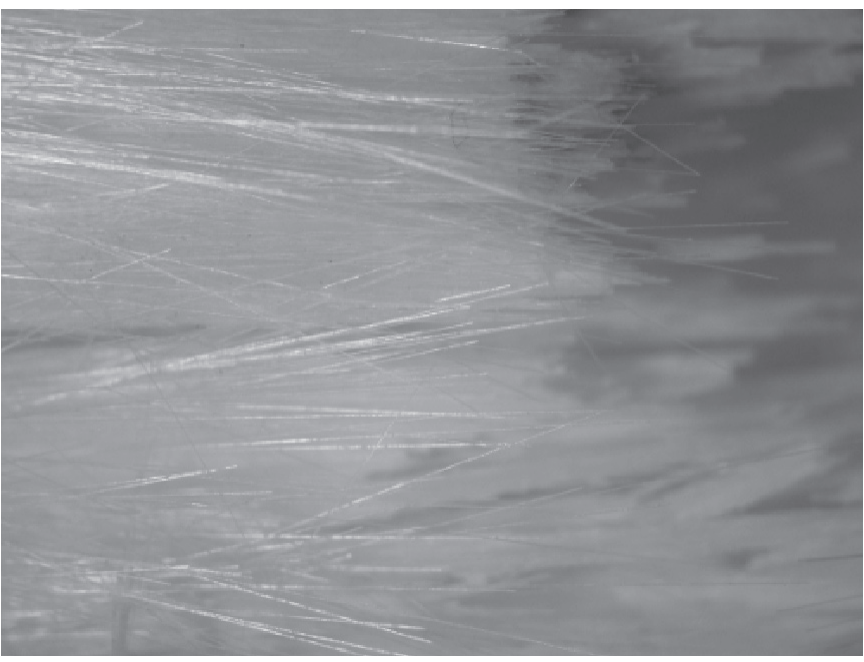

(b)

Figure 14. Macroscopic fracture appearances of CTBN-modified rings: a) fracture region and b) composite layers at fracture region.

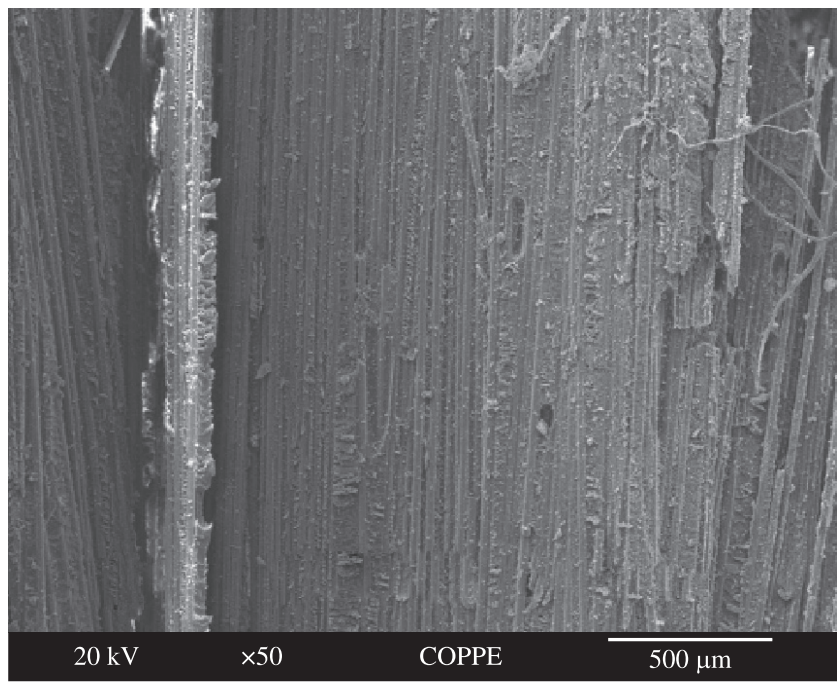

(a)

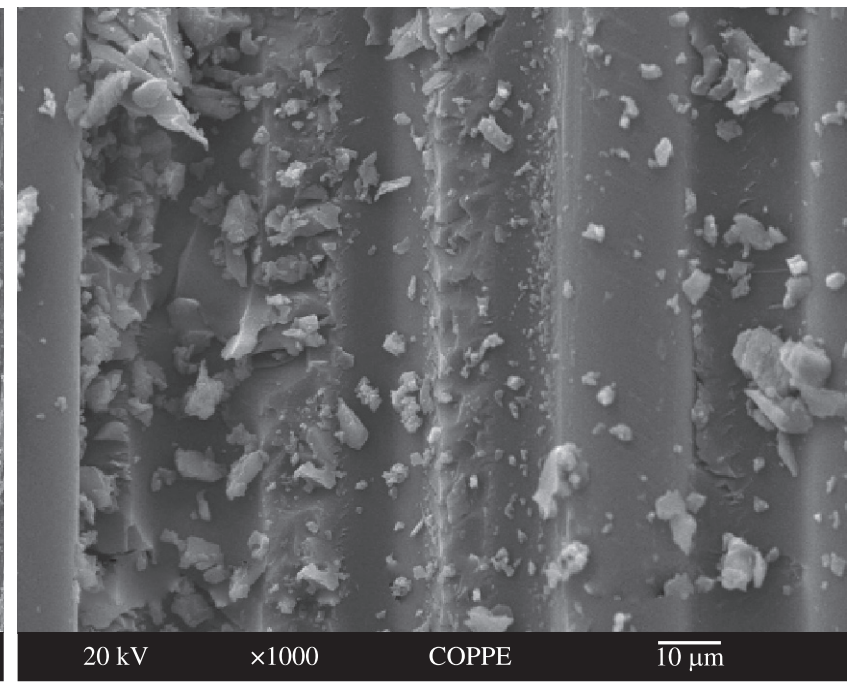

(b)

Figure 15. SEM micrographs of composite rings from neat tubes at magnifications: a) $50 \times$ and b) $1000 \times$.

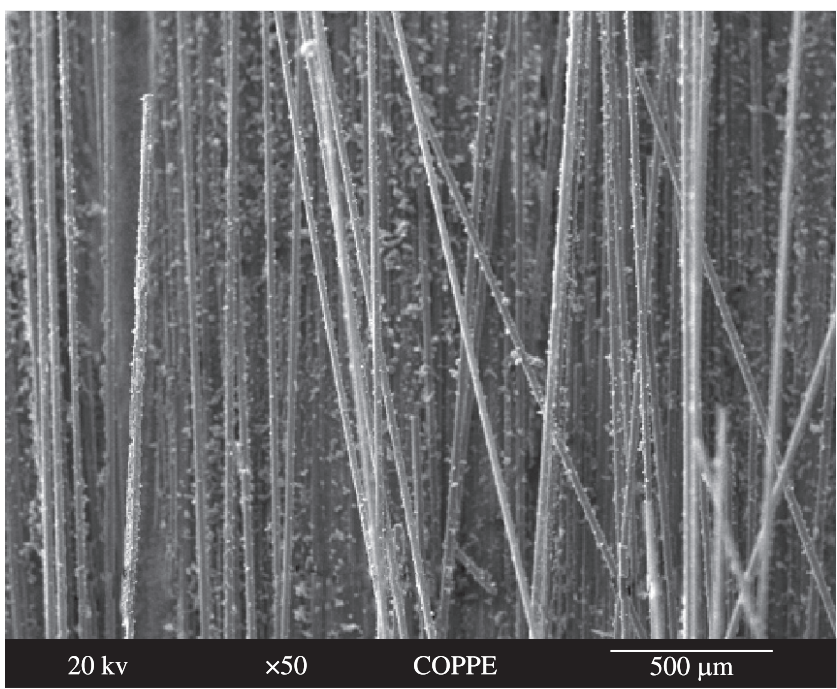

(a)

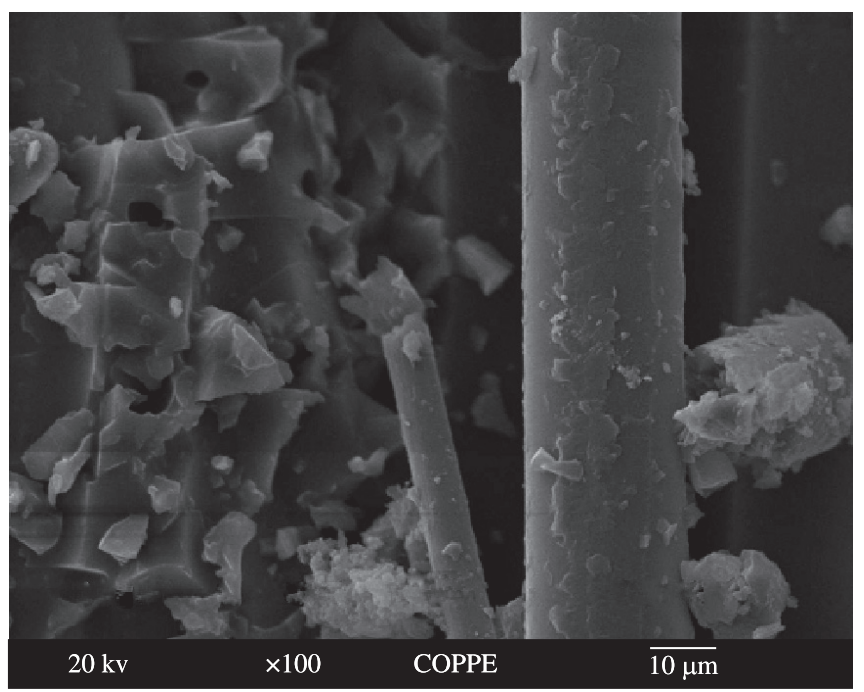

(b)

Figure 16. SEM micrographs of composite rings from CTBN-modified tubes at magnifications: a) $50 \times$ and b) $1000 \times$. 
mode in composite laminates, and that the initiation and propagation of delamination significantly reduce stiffness and strength, and possibly lead to a catastrophic failure of composite structures $^{43}$.

The SEM observations revealed that the delamination occurred mainly in the unmodified specimens. Figure 15 shows that a fracture of fibers occurred in blocks, as previously presented in the macroscopic analysis. In the unmodified samples, it could be also observed the presence of grooves (Figure 15b) on the fracture surface, which are associated to the delamination process, i.e., debonding of upper composite layer. The other way around, in the CTBN-modified specimens, the fibers are quite loose and with a great amount of remaining resin on their surfaces, Figure 16. This observation confirms that rubber modified resin has a better adhesion to fiber surface than unmodified resin.

Herein, it was observed that the increase simultaneous of the strength and strain at fracture in the CTBN-modified composites may be related with the better fiber/matrix interfacial adhesion which promoted an effective load transfer from matrix to fibers. Fractographic analysis confirms these observations.

\section{Conclusion}

There was a reduction in the values of tensile strength and modulus and an increase in the elongation at fracture of modifiedCTBN resin which might be attributed to the lowering in crosslinking density of the polymeric network as the rubber occupies the reaction sites. The fractography study reveals that the presence of CTBN particles led the material to fracture in a way akin to ductile materials. SEM analysis showed also the good adherence between the elastomeric phase and the epoxy matrix which was evidenced by IR analysis. The dynamic mechanical thermal analysis of the polymeric systems showed a reduction in $\mathrm{T}_{\mathrm{g}}$ value with rubber addition which may also be attributed to the lowering in cross-linking density.

In the composite tubes, the rubber addition promoted a better fiber/matrix adhesion. In the split-disk tests, the positive effects of the CTBN were observed on hoop tensile strength of the rings and fracture features. Hoop tensile strength increased from 572.20 to $709.05 \mathrm{MPa}$ (approximately 20\%). Rubber CTBN acted as a plasticizer in epoxy matrix improving the loading and strain distribution to fibers. Adding rubber to the polymeric matrix promoted a simultaneous increase of stress and elongation at fracture, which is not often reported.

\section{Acknowledgements}

The authors acknowledgments the financial assistance of $\mathrm{CNPq}$ e CNPq-CTPetro.

\section{References}

1. Odru P and Poirette Y. Technical and economical evaluation of composite riser systems. In: Proceedings of the Offshore Technology Conference; 2002; Houston, Texas, USA; 2002. p. 1-10. http://dx.doi. org/10.4043/14017-MS

2. Johnson DB, Lo KH and Wu HF. Development of Rigid Composite Risers - a Status Report. SAMPE Journal. 2000; 36(5):26-33.

3. Salama MM. Lightweight materilas for Deepwater Offshore Structures. In: Proceedings of the 18th Annual Offshore Technology Conference; 1986; Houston. Houston: Conoco Inc; 1986. p. 297-304. http://dx.doi. org/10.4043/5185-MS

4. Slagsold L and Gryta OA. Composite Catenary Riser. In: Proceedings of the Workshop on Composite Materials for Offshore Operation; 2001; New York. New York: ABS Publishing; 2001. p. 93-107.

5. Odru P, Poirette Y, Stassen Y, Saint-Marcoux JF and Abergel L. Technical and economical of composite riser systems. In: Offshore Technology Conference-OTC; 2002; Houston. Houston: Technip-Coflexip; 2002. p. 1-10. http://dx.doi.org/10.4043/14017-MS
6. Odru P, Poirette Y, Saipem YS, Marcoux SJF and Abergel L. Composite riser and export line systems for deep offshore applications. In: Proceedings of the 22th International Conference on Arctic Engineering and Offshore Mechanics 2003; ASME 2003. p. 1-10. http://dx.doi. org/10.1115/OMAE2003-37237

7. Lee SB and Rockett J. Interactions of water with unsaturated polyester, vinyl ester and crylic resins. Polymer. 1992; 33:3691-3697. http://dx.doi. org/10.1016/0032-3861(92)90657-I

8. Chikhi N, Fellahi S and Bakar M. Modification of epoxy resin using reactive liquid (ATBN) rubber. European Polymer Journal. 2002; 38:251-164. http://dx.doi.org/10.1016/S0014-3057(01)00194-X

9. Tripathi $G$ and Srivastava D. Effect of carboxyl-terminated poly(butadieneco-acrylonitrile) (CTBN) concentration on thermal and mechanical properties of binary blends of diglycidyl ether of bisphenol-A (DGEBA) epoxy resin. Materials Science \& Engineering A. 2007; 443:262-269. http://dx.doi.org/10.1016/j.msea.2006.09.031

10. Jayadevan KR, Østby E and Thaulow C. Fracture response of pipelines subjected to large plastic deformation under tension. International Journal of Pressure Vessels and Piping. 2004; 81:771-783. http://dx.doi. org/10.1016/j.ijpvp.2004.04.005

11. Thomas R, Yumei D, Yuelong H, Le Y, Moldenaers P, Weimin Y et al. Miscibility, morphology, thermal, and mechanical properties of a DGEBA based epoxy resin toughened with a liquid rubber. Polymer. 2008; 49(10):278-294. http://dx.doi.org/10.1016/j.polymer.2007.11.030

12. Lowe A, Kwon O and Mai Y. Fatigue and fracture bahaviour of novel rubber modified epoxy resin. Polymer. 1995; 37(4):565-572. http://dx.doi. org/10.1016/0032-3861(96)83142-9

13. Tripathi $G$ and Srivastava D. Effect of carboxyl-terminated poly(butadieneco-acrylonitrile) (CTBN) concentration on thermal and mechanical properties of binary blends of diglycidyl ether of bisphenol-A (DGEBA) epoxy resin. Materials Science \& Engineering A. 2007; 443:262-269. http://dx.doi.org/10.1016/j.msea.2006.09.031

14. Tripathi G and Srivastava D. Studies on the physico-mechanical and thermal characteristics of blends of DGEBA epoxy, 3,4 epoxy cyclohexylmethyl, 3', 4'-epoxycylohexane carboxylate and carboxyl terminated butadiene co-acrylonitrile (CTBN). Materials Science and Engineering A. 2008; 496:483-493. http://dx.doi.org/10.1016/j. msea.2008.06.035

15. Chikhi N, Fellahi S and Bakar M. Modification of epoxy resin using reactive liquid (ATBN) rubber. European Polymer Journal. 2002; 38:251-264. http://dx.doi.org/10.1016/S0014-3057(01)00194-X

16. Thomas R, Abraham J, Thomas SP and Thomas S. Influence of carboxylterminated (butadiene-co-acrylonitrile) loading on the mechanical and thermal properties of cures epoxy blends. Journal of Polymer Science Part B: Polymer Physics. 2004; 42: 2531-2544. http://dx.doi.org/10.1002/polb.20115

17. Merz EH, Claver GC and Baer M. Studies on heterogeneous polymeric systems. Journal of Polymer Science. 1956; 22(101):325-341. http://dx.doi.org/10.1002/pol.1956.1202210114

18. Kinloch ASJ, Shaw DAT and Hunston D. Deformation and fracture behaviour of a rubber-toughened epoxy: 2. Failure criteria. Polymer. 1983; 24(10):1355-1363. http://dx.doi.org/10.1016/0032-3861(83)90071-X

19. Bascom WD, Cottington RE, Jones RL and Peyser P. Fracture of EpoxyModified and Elastomer-Modified Epoxy Polymers in Bulk and as Adhesives. Journal of Applied Polymer Science. 1975; 19:2545-2562. http://dx.doi.org/10.1002/app.1975.070190917

20. Abadyan M, Khademi V, Bagheri R, Haddadpour H, Kouchakzadeh MA and Farsadi M. Use of rubber modification technique to improve fracture-resistance of hoop wound composites. Materials and Design. 2009; 30:1976-1984. http://dx.doi.org/10.1016/j.matdes.2008.09.001

21. Kunz SC, Beaumont PWR and Ashby MF. A model for the toughness of epoxy-rubber particulate composites. Journal of Materials Science. 1980; 15(5):1109-1123. http://dx.doi.org/10.1007/BF00551799

22. Kunz S and Beaumont PWR. Low-temperature behaviour of epoxyrubber particulate composites. Journal of Materials Science. 1981; 16(11):3141-3152. http://dx.doi.org/10.1007/BF00540323 
23. Sayer JA, Kunz SC and Assink RA. Polymer Properties. American Chemical Society Division of Polymeric Materials: Science and Engineering. 1983; 49:442-448.

24. Bragaw CG. Theory of Rubber Toughening of Brittle Polymers. Washington: American Chemical Society; 1971. Advances in Chemistry Series, n. 99.

25. Wolock I and Newman SB. Fracture Processes. In: Rosen B, editor. Polymeric Solids: Phenomena and Theory. New York: Interscience; 1964. p. 235-290.

26. Ratna D. Phase separation in liquid rubber modified epoxy mixture. Relationship between curing conditions, morphology and ultimate behavior. Polymer. 2001; 42:4209-4218. http://dx.doi.org/10.1016/S00323861(00)00798-9

27. Thomas R, Durix S, Sinturel C, Omonov T, Goossens S, Groeninckx G et al. Cure kinetics, morphology and miscibility of modified DGEBAbased epoxy resin - Effects of a liquid rubber inclusion. Polymer. 2007; 48:1695-1710. http://dx.doi.org/10.1016/j.polymer.2007.01.018

28. Kinloch AJ and Young RJ. Fracture Behavior of Polymers. London: Applied Science Publisher; 1983.

29. Lin YC and Chen X. Investigation of effect of hygrothermal conditions on epoxy system by fractography and computer simulation. Materials Letters. 2005; 59:3831-3836. http://dx.doi.org/10.1016/j.matlet.2005.06.061

30. Kinloch AJ. Relationships between the microstructure and fracturebehavior of rubber-toughened thermosetting polymers. In: Riew CK, editor. Rubber-toughened plastics. Washington: American Chemical Society; 1989. Advances in Chemistry Series, n. 222.

31. Nigam V, Setua DK and Mathur GN. Characterization of liquid carboxy terminated copolymer of butadiene acrilonitrile modified epoxy resin. Polymer Engineering and Science. 1999; 39(8):1425-1432. http://dx.doi. org/10.1002/pen.11533

32. Ramos VD, Da Costa HM, Soares VLP and Nascimento RSV. Hybrid composites of epoxy resin modified with carboxyl terminated butadiene acrylonitrile copolymer and fly ash microspheres. Polymer Testing. 2005; 24:219-226. http://dx.doi.org/10.1016/j.polymertesting.2004.08.007

33. Salmoria GV, Ahrens CH, Fredel M, Soldi V and Pires ATN. Stereolithography somos 7110 resin: mechanical behavior and fractography of parts post-cured by different methods. Polymer Testing. 2005; 24:157-162. http://dx.doi.org/10.1016/j.polymertesting.2004.09.008

34. Robinette EJ, Ziaee S and Palmese GR. Toughening of vinyl ester resin using butadiene-acrylonitrile rubber modifiers. Polymer. 2004; 45:6143-6154. http://dx.doi.org/10.1016/j.polymer.2004.07.003

35. Christopher WW, Wayne DC and Andy AG. Chemico-diffusion kinetics epoxy-amine resins. Polymer. 1997; 38(13):3251-3261. http://dx.doi. org/10.1016/S0032-3861(96)00882-8

36. May CA. Epoxy Resins - Chemistry and Technology. 2th ed. New York: Marcel Dekker; 1988

37. Ying-Ling L, Chuan-Shao W, Yie-Shun C and Wen-Hsuan H. Preparation, Thermal Properties, and Flame Retardance of Epoxy-Silica Hybrid Resins. Journal of Polymer Science: Part A: Polymer Chemistry. 2003; 41:2354-2367. http://dx.doi.org/10.1002/pola.10778

38. Varley RJ, Hodgkin JH, Hawthorne DG, Simon GP and McCulloch D. Toughening of a trifunctionalepoxy system Part III. Kinetic and morphological study of the thermoplastic modified cure process. Polymer. 2000; 41(9):3425-3436. http://dx.doi.org/10.1016/S00323861(99)00503-0

39. Hunston DL and Bascom WD. Failure behavior of rubber toughened epoxies in bulk, adhesive, and composite geometries. In: Riew CK and Gillham JK, editors. Rubber-modified thermoset resins. Washington: American Chemical Society; 1984. Advances in Chemistry, n. 208.

40. Warrior NA, Turner TA, Robitaille F and Rudd CD. The effect of interlaminar toughening strategies on the energy adbosrption of composite tubes. Composites Part A: applied science and manufacturing. 2004; 35:431-437. http://dx.doi.org/10.1016/j.compositesa.2003.11.001

41. Zhang H, Berglund LA and Ericson M. Rubber-Toughening of Glass Fiber-Epoxy Filament Wound Composites. Polymer Engineering and Science. 1991; 31(14):1057-1063. http://dx.doi.org/10.1002/ pen.760311410

42. Kaynak C, Erdiller ES, Parnas L and Senel F. Use of split-disk tests for the process parameters of filament wound epoxy composite tubes. Polymer Testing. 2005; 24:648-655. http://dx.doi.org/10.1016/j. polymertesting.2005.03.012

43. Mallick PK. Fiber-Reinforced Composites: materials, manufacturing and design. 2th ed. New York: Marcel Dekker; 1993. 